The role of silver in the

radi ophot ol umi nescent propert i es i $n$

si I ver-act i vated phosphate gl ass and sodi um chl ori de crystal

\begin{tabular}{|l|l|}
\hline 著者 & $\begin{array}{l}\text { Kur obor i Toshi o, Zhenga Wang, M yambt o Yuka, } \\
\text { Nant o H dehi t o, Yamant o Takayoshi }\end{array}$ \\
\hline $\begin{array}{l}\text { j our nal or } \\
\text { publ i cat i on t i t l e }\end{array}$ & Opt i cal Nat er i al s \\
\hline vol une & 32 \\
\hline number & 9 \\
\hline page r ange & $1231-1236$ \\
\hline year & $2010-07-01$ \\
\hline URL & ht t p: //hdl . handl e. net /2297/24284 \\
\hline
\end{tabular}




\title{
The role of silver in the photoluminescent properties in silver-activated phosphate glass and sodium chloride crystal
}

\author{
Toshio Kurobori ${ }^{\mathrm{a}, *}$, Wang Zheng ${ }^{\mathrm{a}}$, Yuka Miyamoto ${ }^{\mathrm{b}}$, Hidehito Nanto ${ }^{\mathrm{c}}$, Takayoshi Yamamoto ${ }^{\mathrm{b}}$ \\ ${ }^{a}$ Graduate School of Natural Science and Technology, Kanazawa University, Kakuma-machi, Kanazawa, \\ Ishikawa 920-1192, Japan \\ b Oarai Research Center, Chiyoda Technol Corporation, 3681 Narita-cho, Oarai, Ibaraki 311-1313, Japan \\ c Advanced Material Science R\& D Center, Kanazawa Institute of Technology, 7-1 Oogigaoka, Nonoichi-machi, \\ Ishikawa 921-8812, Japan
}

\begin{abstract}
We have systematically investigated the X-ray-induced radiophotoluminescence (RPL) bands in a silver-activated phosphate glass (PG:Ag), and we have ascribed these bands to $\mathrm{Ag}^{0}, \mathrm{Ag}^{2+}$ and $\mathrm{Ag}_{2}{ }^{+}$centres, using optical characterisation such as absorption, excitation, emission and lifetime measurements. The absorption spectrum of PG:Ag irradiated with X-rays was decomposed into six Gaussian bands on the basis of its strong analogy with irradiated silver-activated sodium chloride ( $\mathrm{NaCl}: \mathrm{Ag})$. We confirmed that blue emission peaking at 450 $\mathrm{nm}$ was connected with the 270 and $345 \mathrm{~nm}$ bands of the excitation spectrum, while orange emission peaking at $560 \mathrm{~nm}$ was associated with the $308 \mathrm{~nm}$ excitation band. Each band of the excitation spectrum was in turn attributed to an $\mathrm{Ag}_{2}{ }^{+}, \mathrm{Ag}^{0}$ or $\mathrm{Ag}^{2+}$ centre by analogy with the RPL of $\mathrm{NaCl}$ :Ag. The excited-state lifetimes for each emissive process were also determined for different X-ray doses. In conclusion, we determined that both blue and orange emissions result from radiation-induced (rather than intrinsic) properties in the range of 1.22 24.5 Gy.
\end{abstract}

PACS: 78.55.Hx, 81.05.Kf

Keywords: Radiophotoluminescence, Phosphate glass, Silver, Optical properties, Sodium chloride, Radiative lifetime

*Corresponding author. fax: +81-76- 234-4132

*E-mail address: laser@kenroku.kanazawa-u.ac.jp (T. Kurobori) 


\section{Introduction}

Controlling precipitation of noble metallic nanoparticles in silver- and gold-doped glass using ultraviolet (UV) photons has been studied since the middle of the last century [1, 2].

Radiophotoluminescence (RPL) has also been examined for a long time in varieties of silver-activated glass and in silver-activated alkali halides [3-7], especially sodium chloride $(\mathrm{NaCl})$, for applications in dosimetry of ionising radiation. In particular, radiation-induced colour centres were extensively studied in silver-activated phosphate glass by Schulman et al. [8], Yokota et al. [9], and Feldmann et al. [10] using optical spectroscopic methods and electron spin resonance (ESR) experiments. Later, nucleation and growth kinetics of Ag particles in glass were investigated in detail using "photosensitive" glass, containing small amounts of silver and cerium, by means of optical spectroscopy [11]. Furthermore, the influence of glass composition on its sensitivity to ionising radiation and on RPL 'build-up' (i.e., the RPL centre concentration increases as a function of time after irradiation) kinetics was demonstrated in silver-activated glass [12]. The synthesis of metal nanoparticles in glass was examined under low and high deposited energy density irradiation conditions [13]. Recently, a RPL dosimeter system using silver-activated glass became commercially available [14] and is being increasingly used for a personal solid-state dosimeter as well as for radiation measurements. 
In addition to these applications, recent advances in high-intensity femtosecond (fs) laser pulses have made it possible to encode various functional microstructures inside transparent materials [15-17]. For example, fabrication and integration of three-dimensional (3-D) microstructures for lab-on-a-chip applications have been extensively demonstrated in FOTURAN $^{\mathrm{TM}}$, a commercially photosensitive glass $[15,18-20]$, using fs laser direct writing followed by thermal treatment and successive wet etching. More recently, intense fs laser pulses with high peak power densities $\left(\sim 100 \mathrm{TWcm}^{-2}\right)$ and high repetition rates $(>200 \mathrm{kHz})$ have enabled direct excitation of the surface plasmon resonance (SPR) of silver nanoparticles without heat treatment [21]. Recently, the interesting research on electron beam induced second harmonic generation has been reported in $\mathrm{Er}^{3+}$ doped $\mathrm{PbO}_{-} \mathrm{GeO}_{2}$ glass containing silver nanoparticles [22]. Such a remarkable phenomenon allows the possibility of 3-D multi-coloured images or bright light-emitting devices (LEDs) with tunable emission colours [23] in this activated glass. Importantly, measurements taken with such intense fs laser pulses have played a significant role $[15,20,24,25]$ in the evaluation of RPL characteristics in photosensitive glass and in the determination of the formation kinetics of related colour centres.

In this paper, we have systematically examined the optical properties of the RPL, including its absorption, excitation, emission and radiative lifetime, to more deeply understand the origin, mechanism, and characteristics of radiation-induced colour centres in 
silver-activated phosphate glass. In particular, each band of the absorption and excitation spectra was attributed to an $\mathrm{Ag}_{2}{ }^{+}, \mathrm{Ag}^{0}$ or $\mathrm{Ag}^{2+}$ centre by comparing the RPL of silver-activated phosphate glass with that of silver-activated sodium chloride.

\section{Experimental Details}

\subsection{Ag-activated phosphate glass and $\mathrm{NaCl}$}

A commercially available GD-450 dosimeter (Chiyoda Technol Corporation, Oarai, Japan) was used as the radiophotoluminescent Ag-activated phosphate glass (designated PG:Ag) sample and was prepared for optical measurements. The samples, approximately 10 $\mathrm{mm} \times 7 \mathrm{~mm} \times 1 \mathrm{~mm}$, were cut to a suitable size from the original glass dosimeter plate. The weight composition of the GD-450 dosimeter was 31.55\% P, 51.16\% O, 6.12\% Al, $11.00 \%$ $\mathrm{Na}$ and $0.17 \%$ Ag. In this study, the samples were washed with distilled water in an ultrasonic bath for $10 \mathrm{~min}$. In addition, the PG:Ag samples were thermally annealed at $400^{\circ} \mathrm{C}$ for $30 \mathrm{~min}$ to eliminate stable colour centres; subsequently, the samples were optically measured several times. Details can be found in Ref. [26].

There were additional samples (PG-glass and NaCl-crystalline matrix) without Ag, are used as reference samples. The $\mathrm{NaCl}$ :Ag samples were grown by the Kyropoulos method 
from melts containing $1 \mathrm{~mol} \% \mathrm{AgCl}$ and were cleaved from a single $\mathrm{NaCl}$ crystal. After cleaving, the samples were subjected to thermal treatment at $500^{\circ} \mathrm{C}$.

\subsection{Measurement and instruments}

All samples were coloured by irradiation from an X-ray unit (dose rate: $12 \mathrm{mGy} / \mathrm{min}$ ) with a copper target operated at $30 \mathrm{kV}$ and $20 \mathrm{~mA}$. In this work, the samples were irradiated such that absorbed doses ranged from 1.22 to 24.5 Gy. Absorption, excitation and emission measurements were performed at room temperature using a Hitachi U-2010 UV-VIS and an F-2500 fluorescence spectrophotometer with the resolution limit of about $1.5 \mathrm{~nm}$, respectively. The fourth harmonic laser beam (266 nm) generated from a Q-switched Nd:YAG laser was used to examine the fading properties of various induced absorption bands. The laser delivered pulses with a full width at half-maximum intensity (FWHM) of 3 ns, a single pulse energy of $1.5 \mathrm{~mJ}$ and a repetition rate of $10 \mathrm{~Hz}$. The exciting beam was not focused (the beam diameter was $5 \mathrm{~mm}$ at the sample surface), to investigate various optical measurements. The peak power density was approximately 2. $6 \mathrm{MW} / \mathrm{cm}^{2}$ for a $266 \mathrm{~nm}$ ns laser.

Radiative lifetime measurements were performed using a time-resolved spectrofluorometer (Horiba Ltd., NAES-1100), which operated based on the time-correlated multi-photon counting technique. A high-pressure-lamp emitted light pulses with stable 
intensities, with FWHM of less than 2 ns and with a repetition rate of $2 \mathrm{kHz}$ [27]. The excitation wavelength was monochromatised using interference filters with a central wavelength of $340 \mathrm{~nm}$. In addition, the RPL from the crystal was observed in a direction perpendicular to that of the excitation beam and analysed by use of suitable filters with central wavelengths of $450 \mathrm{~nm}$ and $560 \mathrm{~nm}$, respectively.

\section{Results and discussion}

\subsection{Absorption and photoluminescence (PL) characteristics}

Figure 1 shows the optical absorption spectra of (a) $0.81-\mathrm{mm}$-thick NaCl:Ag, 0.81-mm-thick NaCl without Ag and (b) 1.0-mm-thick PG:Ag , 1.0-mm-thick PG without Ag, both before and after X-ray irradiation. Prior to X-ray irradiation, absorption spectra of all samples were measured; all samples were colourless, with an absorption edge at about 250 $\mathrm{nm}$ for $\mathrm{NaCl}$ samples and $300 \mathrm{~nm}$ for PG samples. After these measurements, samples with and without Ag were irradiated by X-rays to an absorbed dose of $24.5 \mathrm{~Gy}$ at room temperature. After irradiation, characteristic optical absorption bands at 465, 719 and $226 \mathrm{~nm}$ were observed in $\mathrm{NaCl}$ without $\mathrm{Ag}$ (pure $\mathrm{NaCl}$ ). The first band was identifiable as absorption of $\mathrm{F}$ (i.e., a single electron trapped at an anion vacancy). The $719 \mathrm{~nm}$ band was identifiable as 
$\mathrm{F}_{2}$ (i.e., a pair of nearest-neighbour $\mathrm{F}$ centres along a $<110>$ axis), and the $226 \mathrm{~nm}$ band was identifiable as V (i.e., a tapped hole centre) [5]. The latter band was superposed on the $\mathrm{Ag}^{+}-\mathrm{Ag}^{+}$paired ions at $232 \mathrm{~nm}$.

A 10-min irradiation produced about $7 \times 10^{16} \mathrm{~F}$ centres $\mathrm{cm}^{-3}$ in pure NaCl. By Smakula’s formula, this corresponded to a measured absorption coefficient of $19.8 \mathrm{~cm}^{-1}$ at the F-band maximum (465 nm) and the FWHM bandwidth of $0.43 \mathrm{eV}$. The oscillator strength $f$ was used to extract the value of 0.86 for the $\mathrm{F}$ band in $\mathrm{NaCl}$ [5]. In contrast, for irradiated PG without Ag, an absorption band appeared at about 450-550 nm; from analogy with alkali halides, this band is presumably caused by formation of intrinsic lattice defects such as an F band.

For the NaCl:Ag and PG:Ag samples, broad absorption spectra induced by X-ray irradiation appeared in the range from 250 to $600 \mathrm{~nm}$. As will be shown later, the broad absorption spectra consisted of six bands for both samples. Also, the absorption coefficient of the irradiated PG:Ag was about three times larger than that of the irradiated $\mathrm{NaCl}$ :Ag under the same absorbed dose of 24.5 Gy.

Figure 2 shows the normalised excitation and PL spectra of non-irradiated (a) NaCl:Ag and (b) PG:Ag. At first, an absorption spectrum in the range from 190 to $250 \mathrm{~nm}$ was measured with a 0.17 -mm-thick $\mathrm{NaCl}$ :Ag plate, due to the high concentration $(1 \mathrm{~mol} \%)$ of silver. Consequently, three peaks appeared in the absorption spectrum (not shown here) at 209, 218 and $232 \mathrm{~nm}$. Similar absorption peaks have been previously reported [3-6]. The first two 
bands, attributed to $4 \mathrm{~d}^{10}-4 \mathrm{~d}^{9} 5 \mathrm{~s}$ transitions, resulted from the isolated $\mathrm{Ag}^{+}$ions in the lattice (type I centres). The third band was ascribed to $\mathrm{Ag}^{+}-\mathrm{Ag}^{+}$paired ions (type II centres), as it was only found in crystals with heavily doped $\mathrm{NaCl}: \mathrm{Ag}$. The $\mathrm{Ag}^{+}-\mathrm{Ag}^{+}$paired bands at $232 \mathrm{~nm}$ were mostly concealed by a neighbouring much stronger isolated $\mathrm{Ag}^{+}$band leaving a shoulder at room temperature. The band at $232 \mathrm{~nm}$ was assigned to $\mathrm{Ag}^{+}-\mathrm{Ag}^{+}$paired ions; as first pointed out by Etzel et al. [4], this band intensity was proportional to the square of the concentration of silver ions in the highly doped crystal. As shown in Fig. 2a, type I centres at $218 \mathrm{~nm}$ produced predominantly 246-nm emission but also some 386-nm emission, while type II centres at $232 \mathrm{~nm}$ produced stronger emission of 386-nm light than of 246-nm light. According to a previous study [7], the $\mathrm{Ag}^{+}-\mathrm{Ag}^{+}$paired ions in $\mathrm{NaCl}$ :Ag occupy two cation sites that hold a chlorine ion between them, observed through the results of polarisation properties of the fluorescence.

As shown in Fig. 2b, the 232-nm excitation in PG:Ag produced PL predominantly at 302 $\mathrm{nm}$, with a Stokes shift of nearly half that of $\mathrm{NaCl}$ :Ag. The position of the 232-nm band in PG:Ag agreed well with that of the 229-nm band in NaCl:Ag.

\subsection{Peak fitting analysis}


As shown in Fig. 1, absorption spectra with many peaks were observed in the irradiated NaCl:Ag and PG:Ag samples in the range from 250 to $600 \mathrm{~nm}$. Figure 3 shows the absorption spectra (solid line) of the irradiated (a) NaCl:Ag and (b) PG:Ag under an absorbed dose of 24.5 Gy. In addition, the absorption spectra were decomposed into the sum of separate Gaussian bands (indicated by dashed lines).

In the case of $\mathrm{NaCl}: \mathrm{Ag}$, the absorption band as shown in Fig. 3a could be decomposed into six bands, peaking at 224, 276, 308, 335, 382 and $443 \mathrm{~nm}$. When the silver-activated crystals were irradiated with X-rays, several new bands appeared next to the "F"-band. These new bands are respectively called the "A”, “B”, “C”, "D” and "E” bands [5]. Parfianovich et al. [6] observed radiation-induced bands at “B” (peaking at $276 \mathrm{~nm}$ ), “C” (305 nm), “D” (335 $\mathrm{nm})$ and "E” (400 nm). The peak positions of each band are in good agreement with those of the above decomposed results. Bands “A” (232 nm) and "F" (465 nm), as shown in Fig. 1a, are due to $\mathrm{Ag}^{+}-\mathrm{Ag}^{+}$paired ions and $\mathrm{F}$ centres, respectively. Also, the peak positions of bands "E" and "F" almost overlap the F band at $465 \mathrm{~nm}$. Thus, the absorption peaks of the RPL are attributed mainly to bands "B”, “C” and "D”. The origin of these bands in $\mathrm{NaCl}$ :Ag has been already clarified [3] as follows: bands “ $\mathrm{B}$ ” and “ $\mathrm{D}$ ” are related to $\mathrm{F}$ and $\mathrm{F}_{2}$ centres with neighbouring $\mathrm{Ag}^{+}$, respectively, and the narrow “C” band is strongly related to the $\mathrm{Ag}^{0}$ centres located at large lattice defects. 
The insets of Figs. 3a and b show the absorption spectra of $\mathrm{NaCl}$ :Ag and PG:Ag recorded before irradiation (Curve 1), immediately after X-ray irradiation with a dose of 24.5 Gy (Curve 2), after annealing the X-ray irradiated sample for one day at room temperature (Curve 3), and immediately after bleaching with 266-nm light (Curve 4) from a Q-switched Nd:YAG laser for 1 min with the peak power density of approximately 2. 6 $\mathrm{MW} / \mathrm{cm}^{2}$. As shown in the inset of Fig. 3a, after annealing the X-ray irradiated sample for one day in the dark, a decrease in intensity of bands "E" and "F" was prominently observed. While these bands decreased in intensity (not shown here), the absorption band at $233 \mathrm{~nm}$ attributed to the $\mathrm{Ag}^{+}-\mathrm{Ag}^{+}$paired ions increased in intensity by nearly a factor of 2.5 . Furthermore, after the laser beam irradiation at 266 nm, bands "B", "C" and " $D$ " decreased in intensity, while the $233 \mathrm{~nm}$ band and the F band at $465 \mathrm{~nm}$ strengthened.

In the case of PG:Ag, the appropriate absorption bands as shown in Fig. 3b could be also decomposed into six absorption bands from “A" to "F”, peaking at 225, 252, 270, 307, 354 and 424, respectively. In contrast to the $\mathrm{NaCl}$ :Ag sample, after annealing the X-ray irradiated PG:Ag sample for one day in the dark, the absorption of PG:Ag increased in the range from 250 to $320 \mathrm{~nm}$ and decreased slightly in the range from 400 to $600 \mathrm{~nm}$, as shown in the inset of Fig. 3b. Such a phenomenon for RPL behaviour in PG:Ag is well known as 'build-up' kinetics [9, 12]. After the 266-nm beam irradiation, the whole absorption spectra in PG:Ag decreased monotonically from 250- to 600-nm range. 


\subsection{Excitation and radiophotoluminescence (RPL) characteristics}

When $\mathrm{Ag}^{+}$-doped glass is irradiated by $\mathrm{X}$ - or gamma rays, silver in the glass may exist as $\mathrm{Ag}^{+}$, as $\mathrm{Ag}^{0}$ (i.e., trapped electron centres) and as $\mathrm{Ag}^{2+}$ (i.e., trapped hole centres). The radiation-induced $\mathrm{Ag}^{0}$ and $\mathrm{Ag}^{2+}$ centres are paramagnetic and are easily detected in the glass using ESR [9, 10] spectroscopy. In addition, the presence of these colour centres in glasses has been confirmed by irradiation using intense fs laser pulses [25].

Figure 4 shows the excitation and emission spectra after X-ray irradiation for (a) NaCl:Ag and (b) PG:Ag. An absorption spectrum (Curve 1) is also shown for comparison. Though the absorption spectra can be decomposed into six bands as shown in Figs. 3a and b, the excitation spectra for both samples are not as complicated as the absorption spectra. For $\mathrm{NaCl}$ :Ag, the excitation spectrum (Curve 2) detected using an emission wavelength of $560 \mathrm{~nm}$ (orange emission) consists of two explicit peaks at 289 and $339 \mathrm{~nm}$ and a 233-nm peak due to the $\mathrm{Ag}^{+}-\mathrm{Ag}^{+}$paired ions. The former peaks are strongly overlapped by bands " $\mathrm{B}$ " and "C" in the corresponding absorption spectrum, and the latter is overlapped by band " $D$ ". Bands " $E$ " and "F" in the absorption spectrum do not contributed to the RPL in the visible region. In addition, the excitation spectrum detected at $450 \mathrm{~nm}$ (blue emission, data not shown) is 
mainly related to the 233-nm absorption band, which is due to $\mathrm{Ag}^{+}-\mathrm{Ag}^{+}$paired ions, and to the 281-nm band, which is due to F centres with minor contributions from neighbouring $\mathrm{Ag}^{+}$.

In the case of PG:Ag, the excitation spectra (Curves 2 and 3) consist of two different excitation phenomena, as shown in Fig. 4b. One peak is detected at $308 \mathrm{~nm}$ (Curve 2), which excites emission detected at $560 \mathrm{~nm}$ (orange). Additionally, 450-nm emission (blue) is excited by a combination of peaks at 270 and $345 \mathrm{~nm}$ (Curve 3). The former corresponds to the decomposed 307-nm Gaussian band, while the latter correspond to the decomposed 270 - and 354-nm bands, as shown in Fig. 3b. In PG:Ag, the blue emission (Curves 5 and 6) and some portion of the orange emission are strongly related to the 270- and 345-nm excitation bands. This is completely analogous to the blue emission of $\mathrm{NaCl}$ :Ag associated with bands "B" (i.e., the F centres with neighbouring $\mathrm{Ag}^{+}$) and "C" (i.e., $\mathrm{Ag}^{0}$ atoms). Therefore, based on the above results, the absorption band centred at $345 \mathrm{~nm}$ in the irradiated PG:Ag may be attributed to $\mathrm{Ag}^{0}$ (reaction: $\mathrm{Ag}^{+}+e^{-} \rightarrow \mathrm{Ag}^{0}$ ) centres. This attribution is further supported by fs laser measurements [21, 24, 25]. The other blue band at $270 \mathrm{~nm}$ in PG:Ag may be also related to the $\mathrm{Ag}_{2}{ }^{+}$(reaction: $\mathrm{Ag}^{0}+\mathrm{Ag}^{+} \rightarrow \mathrm{Ag}_{2}^{+}$). In contrast, the orange emission (Curve 4) in PG:Ag is related to the absorption band at $308 \mathrm{~nm}$ (Curve 2), which may be attributed to $\mathrm{Ag}^{2+}$ (reaction: $\mathrm{Ag}^{+}+h^{+} \rightarrow \mathrm{Ag}^{2+}$ ) centres.

To assign each band to $\mathrm{Ag}^{0}, \mathrm{Ag}_{2}{ }^{+}$and $\mathrm{Ag}^{2+}$ centres, heat treatments at temperatures taken from 27 to $250^{\circ} \mathrm{C}$ in increments of $50^{\circ} \mathrm{C}$ were performed. The samples were kept for one day 
in the dark after X-ray irradiation, and then they were annealed at each temperature for $30 \mathrm{~min}$. After being held for another one day, absorption, excitation and emission of the RPL spectra were measured at room temperature. Finally, the samples were annealed at $400^{\circ} \mathrm{C}$ for $30 \mathrm{~min}$ to eliminate stable colour centres before they were then used again. Selected from this body of data, absorption and excitation spectra at annealing temperatures of $27^{\circ} \mathrm{C}$ and $250^{\circ} \mathrm{C}$ are presented here and are shown in Fig. 5. The band with a peak at $345 \mathrm{~nm}$, due to the $\mathrm{Ag}^{0}$ centres, shifted from $345 \mathrm{~nm}$ (Curve 5) to $330 \mathrm{~nm}$ (Curve 6) with increasing annealing temperature. Similar blue shift of the optical properties of $\mathrm{Ag}^{0}$ centres in glass has been already reported [13]. Similar phenomena also occurred for the 270-nm band, which may be ascribed to the $\mathrm{Ag}_{2}{ }^{+}$centres as described above. This band shifted from $270 \mathrm{~nm}$ (Curve 5) to $260 \mathrm{~nm}$ (Curve 6) with increasing annealing temperature. This blue shift can be explained by the reaction of neutral silver with $\mathrm{Ag}^{+}$, i.e., $\mathrm{Ag}^{0}+\mathrm{Ag}^{+} \rightarrow \mathrm{Ag}_{2}{ }^{+}$, which therefore shifts the position of the $\mathrm{Ag}^{0}$ band. The $\mathrm{Ag}_{2}{ }^{+}$band with coupling to $\mathrm{Ag}^{0}$ also shifts its position from the original.

In addition, another larger band peaking at $244 \mathrm{~nm}$ (Curve 6) appeared after annealing at $250^{\circ} \mathrm{C}$. This may be attributed to formation of $\mathrm{Ag}_{3}{ }^{2+}\left(\mathrm{Ag}^{+}+\mathrm{Ag}_{2}{ }^{+} \rightarrow \mathrm{Ag}_{3}{ }^{2+}\right)$ or $\mathrm{Ag}_{3}{ }^{+}\left(\mathrm{Ag}^{0}+\right.$ $\mathrm{Ag}_{2}{ }^{+} \rightarrow \mathrm{Ag}_{3}{ }^{+}$) from diffusion and dimerisation of $\mathrm{Ag}_{2}{ }^{+}$ions. In contrast, the band peaking at $308 \mathrm{~nm}$ (Curves 3 and 4) due to $\mathrm{Ag}^{2+}$ without coupling to $\mathrm{Ag}^{0}$ centres remained in essentially the same peak position; it simply increased in intensity with increasing temperature. 
From the complete set of results taken from $27^{\circ} \mathrm{C}$ to $250^{\circ} \mathrm{C}$ in increments of $50^{\circ} \mathrm{C}$, the maximum intensity of the excitation bands peaking at 270 and $345 \mathrm{~nm}$ for blue emission occurred at $70^{\circ} \mathrm{C}$. These bands then decreased gradually in intensity with increasing temperature. The intensity of the band peaking at $308 \mathrm{~nm}$ for the orange emission increased monotonically with increasing temperature.

\subsection{RPL decay curve analysis}

Figure 6 shows a typical example of the decay curves of the PL and RPL for non-irradiated and irradiated NaCl:Ag and PG:Ag. The RPL decay curves were taken for both samples, which had been irradiated at a dose of 24.5 Gy. Furthermore, the PG:Ag sample was irradiated with various doses ranging from 1.22 to 24.5 Gy to examine the dose dependence of the RPL radiative lifetime. By excitation into the same $230 \mathrm{~nm}$ band, the PL decay curves (Curve 3) were detected at wavelengths of 386 and $302 \mathrm{~nm}$ for the NaCl:Ag and PG:Ag, respectively, as shown in Figs. 2a and b. The lifetime of the PL was 5.21 ns for NaCl:Ag and 8.6 $\mu$ s for PG:Ag. RPL decay curves were measured at the center central wavelengths of $450 \mathrm{~nm}$ (Curve 2) and $560 \mathrm{~nm}$ (Curve 1) for both samples by excitation into the same 340-nm band. Table 1 summarises the radiative lifetime data as measured for the PL and RPL of NaCl:Ag and PG:Ag. These values were obtained by fitting single- and/or 
double-exponential components to the decay curves using a least-squares iteration decomposition method. Table 2 shows the radiative lifetime results for PG:Ag with different doses of 24.5, 12.2, 2.45 and 1.22 Gy. Lifetime values with large errors were observed for the decay curves with longer lifetimes (corresponding to orange emission) due to the limited time-scale capability (a total of $10 \mu$ s) of the experimental apparatus.

Two RPL emission bands in the irradiated PG:Ag were observed. As Table 1 shows, the lifetime of the blue emission at $450 \mathrm{~nm}$ is much shorter than that of the orange at $560 \mathrm{~nm}$. Few results have reported on the radiative lifetime of RPL in glass [28, 29]. Time-resolved luminescence, excited using a pulsed $\mathrm{N}_{2}$ laser as an excitation source, has been reported in dosimeter glass [28]. The experiment used a dose range of 1 - 20 mGy and studied a fixed wavelength region centred at $600 \mathrm{~nm}$ (orange emission). For such a low-dose sample, only a narrow middle-term region (delay time: $2 \mu \mathrm{s}<\unlhd 20 \mu \mathrm{s}$ ) was thought to be the radiation-induced component, while other regions (i.e., short-term ( $\mathrm{t} \leq 2 \mu \mathrm{s})$ and long-term (t $>20 \mu \mathrm{s})$ components) were thought to be related to dirt or exposure to a predose. Also, time-resolved luminescence spectra at $450 \mathrm{~nm}$ and $600 \mathrm{~nm}$ were reported [29] in a methaphosphate glass that had been irradiated by gamma-rays at doses of 1.8 and $123 \mathrm{~Gy}$. In this work, for the high-dose sample, the short-term component was not a predose component but was radiation-induced. However, due to a poor time resolution (gate time: 5 ns) of the experimental apparatus, accurate lifetime values have not yet been reported. 
In the present work, we observe no predose for the blue and orange emission bands of the RPL in the dose range of 1.22 - 24.5 Gy. The lifetime values for both emissions decreased monotonically with increasing absorbed dose. In this work, all of the measured components of the decay curves were radiation-induced components.

\section{Conclusions}

We have measured optical absorption as well as radiophotoluminescence excitation, emission and lifetime in non-irradiated and irradiated silver-activated phosphate glass (PG:Ag). Our purpose was to clarify the origin and mechanism of the X-ray induced colour centres. The RPLs of PG:Ag and NaCl:Ag were systematically compared. From the data obtained the following conclusions could be extracted:

(1) According to RPL absorption study of X-ray irradiated silver-activated phosphate glass (PG:Ag) in correlation to $\mathrm{NaCl}$ :Ag, it was established that the absorption coefficient of PG:Ag is higher than that of $\mathrm{NaCl}$ :Ag, with maximum at $315 \mathrm{~nm}$ and at $275 \mathrm{~nm}$, respectively.

(2) The absorption bands of the RPL in PG:Ag and in NaCl:Ag could be decomposed into new six Gaussian absorption bands, marked as “A” to “F”, peaking at 224, 276, 308, 335, 382 and $443 \mathrm{~nm}$ for $\mathrm{NaCl}: \mathrm{Ag}$ and at 225, 252, 270, 307, 354 and $424 \mathrm{~nm}$ for PG:Ag samples, respectively. 
(3) Blue emission at $450 \mathrm{~nm}$ was connected to the 270- and 345-nm bands of the excitation spectrum. These bands were attributed to the $\mathrm{Ag}_{2}{ }^{+}$and $\mathrm{Ag}^{0}$ centres, respectively. The radiation-induced colour centres containing $\mathrm{Ag}^{0}$ centres were sensitive to annealing temperature, and the peak of the band shifted to shorter wavelength with increasing temperature, as shown in Figs. 4 and 5.

(4) The orange emission at $560 \mathrm{~nm}$ was associated with the 308-nm band in the excitation spectrum. This optical activity was due to the $\mathrm{Ag}^{2+}$ centres. No blue shift was observed for the spectra of the $\mathrm{Ag}^{2+}$ centres with increasing temperature, as shown in Fig. 5.

(5) In the absorbed dose range from 1.22 to 24.5 Gy, no components of the blue and orange emission were attributable to dirt or any predose. It was established that all components of the blue and orange emissions in PG:Ag were radiation-induced origins and lifetime values tended to be longer for the blue and orange RPLs with decreasing absorbed dose according to the data in Table 2.

\section{Acknowledgements}

We would like to thank K. Hatakeyama and C. Zhao for their technical assistance in the experiments. 


\section{Figure captions}

Fig. 1. Absorption spectra of (a) $\mathrm{NaCl}$ Ag, $\mathrm{NaCl}$ without $\mathrm{Ag}$ and (b) PG:Ag, PG without Ag, both before and after X-ray irradiation with a dose of $24.5 \mathrm{~Gy}$.

Fig. 2. Normalised excitation and PL spectra of non-irradiated (a) NaCl:Ag and (b) PG:Ag.

Fig. 3. Absorption spectra (solid line) of the irradiated (a) NaCl:Ag and (b) PG:Ag under a dose of $24.5 \mathrm{~Gy}$. The absorption spectra were decomposed into the sum of separate Gaussian bands (dashed lines). The insets show the absorption spectra recorded before irradiation (Curve 1), immediately after $\mathrm{X}$-ray irradiation (Curve 2), after annealing the X-ray irradiated sample for one day (Curve 3), and immediately after bleaching with the 266-nm light (Curve 4), respectively.

Fig. 4. Excitation and emission spectra after X-ray irradiation for (a) $\mathrm{NaCl}$ :Ag and (b) PG: Ag. The absorption spectrum (Curve 1) is also shown. For NaCl:Ag, excitation detected at $560 \mathrm{~nm}$ (Curve 2), RPL excited at $289 \mathrm{~nm}$ (Curve 3) and RPL excited at $339 \mathrm{~nm}$ (Curve 4). For PG:Ag, excitation detected at 560 $\mathrm{nm}$ (Curve 2), excitation detected at $450 \mathrm{~nm}$ (Curve 3), RPL excited at 308 $\mathrm{nm}$ (Curve 4), RPL excited at $270 \mathrm{~nm}$ (Curve 5) and RPL excited at $370 \mathrm{~nm}$ (Curve 6).

Fig. 5. Absorption (Curves 1 and 2) and excitation (Curves 3-6) spectra of the irradiated PG:Ag at different annealing temperatures. Absorption after X-ray irradiation with a dose of 24.5 Gy (Curve 1), absorption after annealing of Curve 1 at $250{ }^{\circ} \mathrm{C}$ for $30 \mathrm{~min}$ (Curve 2), excitation detected at $560 \mathrm{~nm}$ without annealing (Curve 3), excitation detected at $560 \mathrm{~nm}$ after annealing (Curve 4), excitation detected at $450 \mathrm{~nm}$ without annealing (Curve 5), and excitation detected at $450 \mathrm{~nm}$ after annealing (Curve 6), respectively.

Figure 6 The decay curves of the PL and RPL for (a) NaCl:Ag and (b) PG:Ag. For both samples, RPL detected at $560 \mathrm{~nm}$ (Curve 1), RPL detected at $450 \mathrm{~nm}$ (Curve 2), PL (Curve 3), and excitation pulse waveform (Curve 4). The inset shows the amplification of the time-scale. 


\section{Table captions}

Table 1 Radiative lifetime results as measured for the PL and RPL of NaCl:Ag and PG:Ag at room temperature under a dose of 24.5 Gy.

Table 2 Radiative lifetime results for the RPL of PG:Ag at room temperature with different X-ray doses. 


\section{References}

[1] A.E. Badger, F. A. Hummel, Phys. Rev. 68 (1945) 231.

[2] S. D. Stookey, Ind. Eng. Chem. 41 (1949) 856.

[3] E. Burstein, J. J. Oberly, B. Henvis , M. White, Phys. Rev. 86 (1955) 255.

[4] H. W. Etzel, J. H. Schulman, R. J. Ginther , E. W. Claffy, Phys. Rev. 85 (1952) 1063.

[5] J. H. Schulman , W. D. Compton, Color Centers in Solids (Pergamon Press, Inc., New York, 1963) p.160.

[6] L. A. Parfianovich, E. E. Penzina , Yu. G. Penzin, Izvestiya VUZ, Fizika, No.2 (1965) 150.

[7] R. Onaka, S. Yano , T. Mabuchi, Science of Light 15 (1966) 68.

[8] J. H. Schulman, R. J. Ginther , C. C. Klick, R. S. Alger , R. A. Levy, J. Appl. Phys. 22 (1951) 1479.

[9] R. Yokota , H. Imagawa, J. Phys. Soc. Japan 23 (1966) 1038.

[10] T. Feldmann , A. Treinin, J. Chem. Phys. 47 (1967) 2754.

[11] U. Kreibig, Appl. Phys. 10 (1976) 255.

[12] A. V. Dmitryuk, S. E. Paramzina, A. S. Perminov, N. D. Solov'eva, N. T. Timofeev, J. Non-Cryst. Solids 202 (1996) 173.

[13] R. Espiau de Lamaestre, H. Béa, H. Bernas, J. Belloni , J. L. Marignier, Phys. Rev. B 76 (2007) 205431.

[14] Technical Information for RPL Glass Dosimeter, Asahi Techno Glass Corporation, Tokyo (2000).

[15] Y. Shimotsuma, K. Hirao, P. G. Kazansky , J. Qiu, Jpn. J. Appl. Phys. 44 (2005) 4735.

[16] K. Kawamura, M. Hirano, T. Kurobori, D. Takamizu, T. Kamiya , H. Hosono, Appl. Phys. Lett. 84 (2004) 311.

[17] T. Kurobori, T. Sakai , S. Aoshima, Phys. Status Solidi A 204 (2007) 699.

[18] Y. Cheng, K. Sugioka , K. Midorikawa, Appl. Surf. Sci. 248 (2005) 172.

[19] F. E. Livingston, P. M. Adams , H. Helvajian, Appl. Surf. Sci. 247 (2005) 526.

[20] D. M. Krol, J. Non-Crys. Solids 354 (2008) 416.

[21] N. H. Ma, H. L. Ma, M. J. Zhong, J. Y. Yang, Y. Dai, G. Ye, Z. Y. Yue, G. H. Ma , J. R. Qiu, Mater. Lett. 63 (2009) 151.

[22] L. R.. P. Kassab, R. Miedzinski, I. V. Kityk, J. Ebothe, D. M. Da Silva, Ali H. Reshak, J. Mater. Sci.: Mater. Electron. 20 (2009) 87.

[23] M. Eichelbaum , K. Rademann, Adv. Func. Mater. 19 (2009) 2045.

[24] Q. Zhao, J. Qiu, X. Jiang, C. Zhao , C. Zhu, Opt. Express, 12 (2004) 4035.

[25] Y. Watanabe, G. Namikawa, T. Onuki, K. Nishio , T. Tsuchiya, Appl. Phys. Lett. 78 (2001) 2125. 
[26] Y. Ihara, A. Kishi, W. Kada, F. Sato, Y. Kato, T. Yamamoto , T. Iida, Rad. Meas. 43 (2008) 542.

[27] T.Kurobori, T. Kanasaki, Y. Imai , N. Takeuchi, J. Phys. C, Solid State Phys. 21 (1988) L397.

[28] H. Schneckenburger, D. F. Regulla , E. Onsöld, Appl. Phys. A26 (1981) 23.

[29] T. Miyoshi, Jpn. J. Appl. Phys. 29 (1990) 948. 


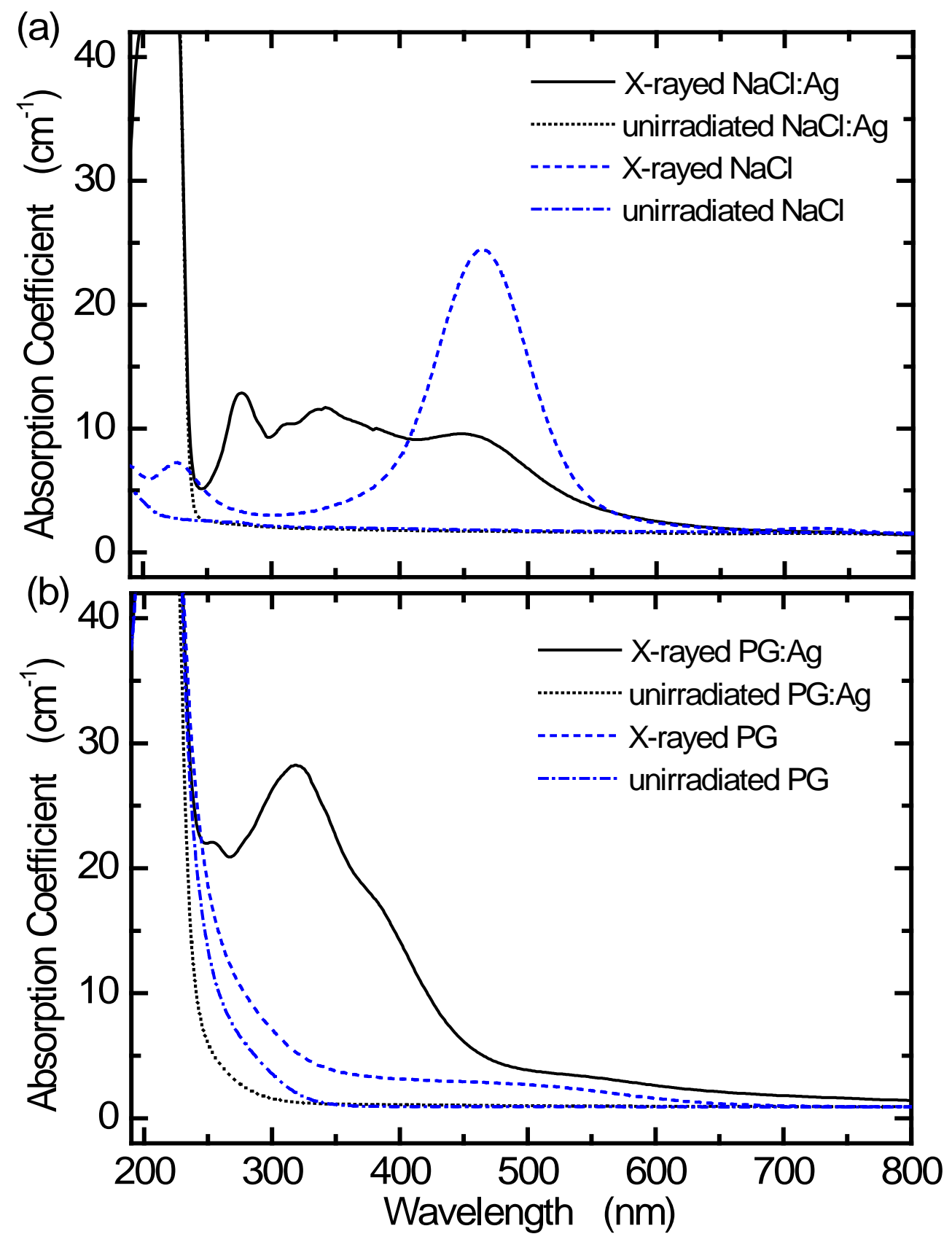

Fig. 1 (a), (b)

T. Kurobori 

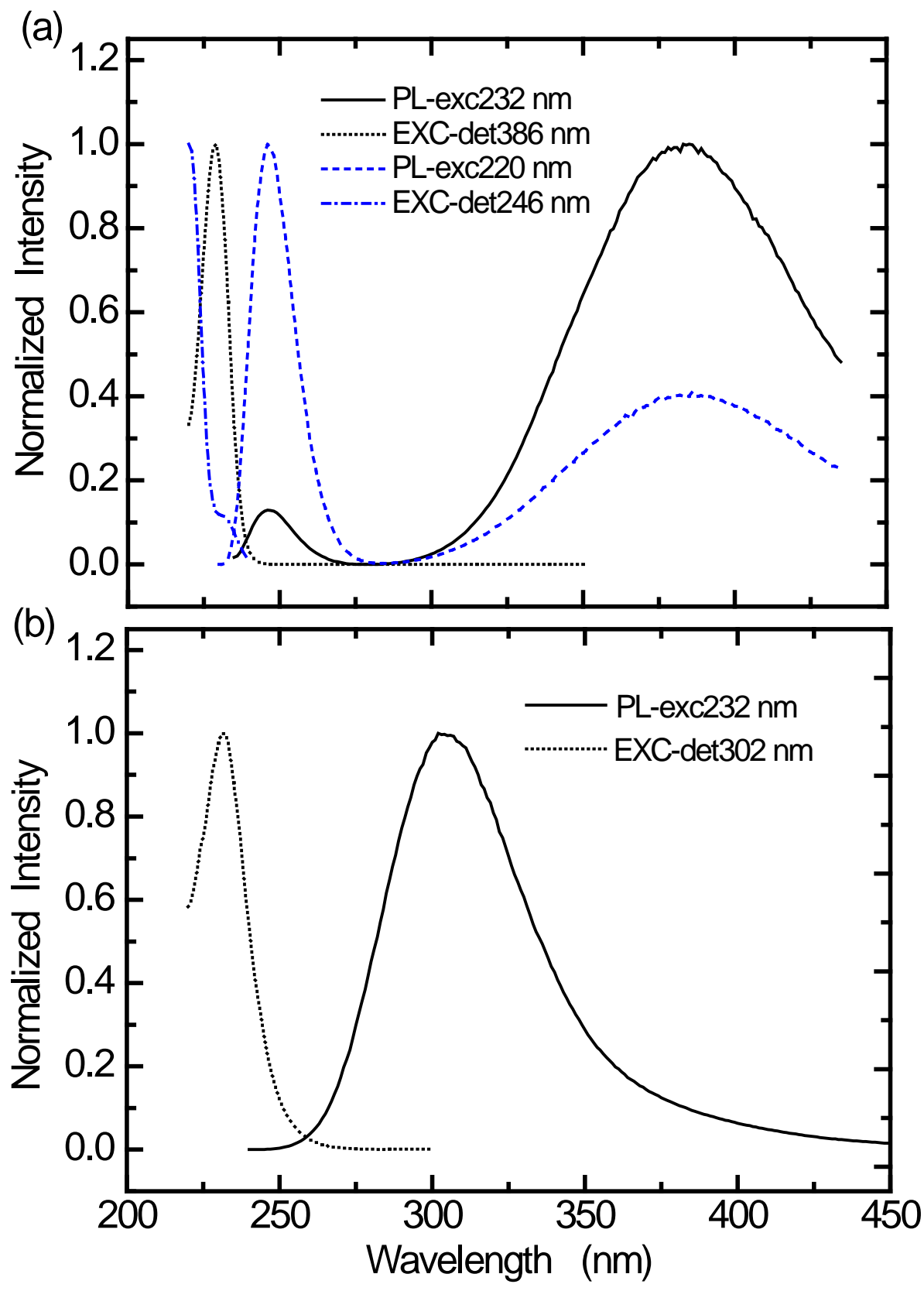

Fig. 2 (a), (b) 

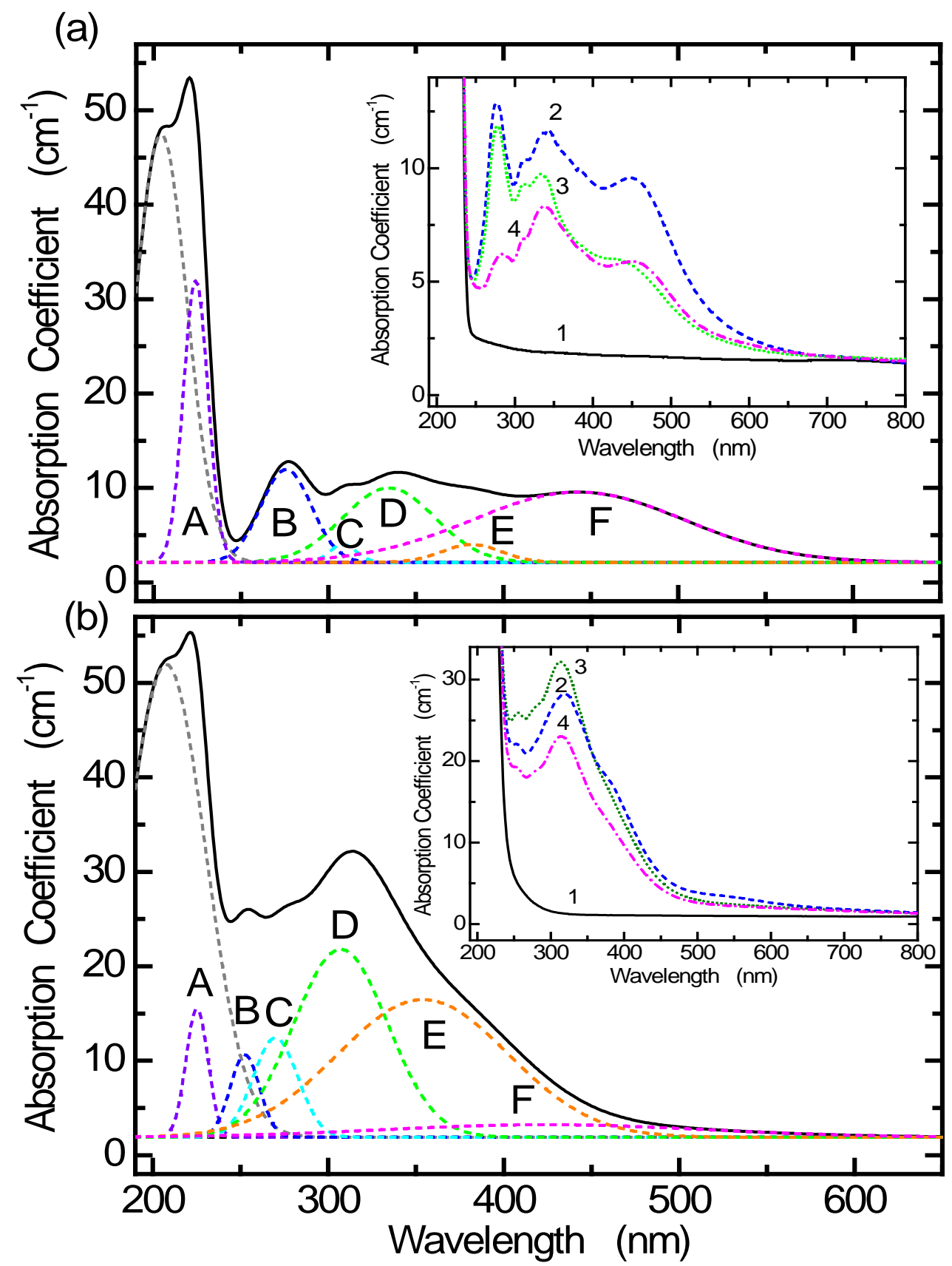

Fig. 3 (a), (b) 

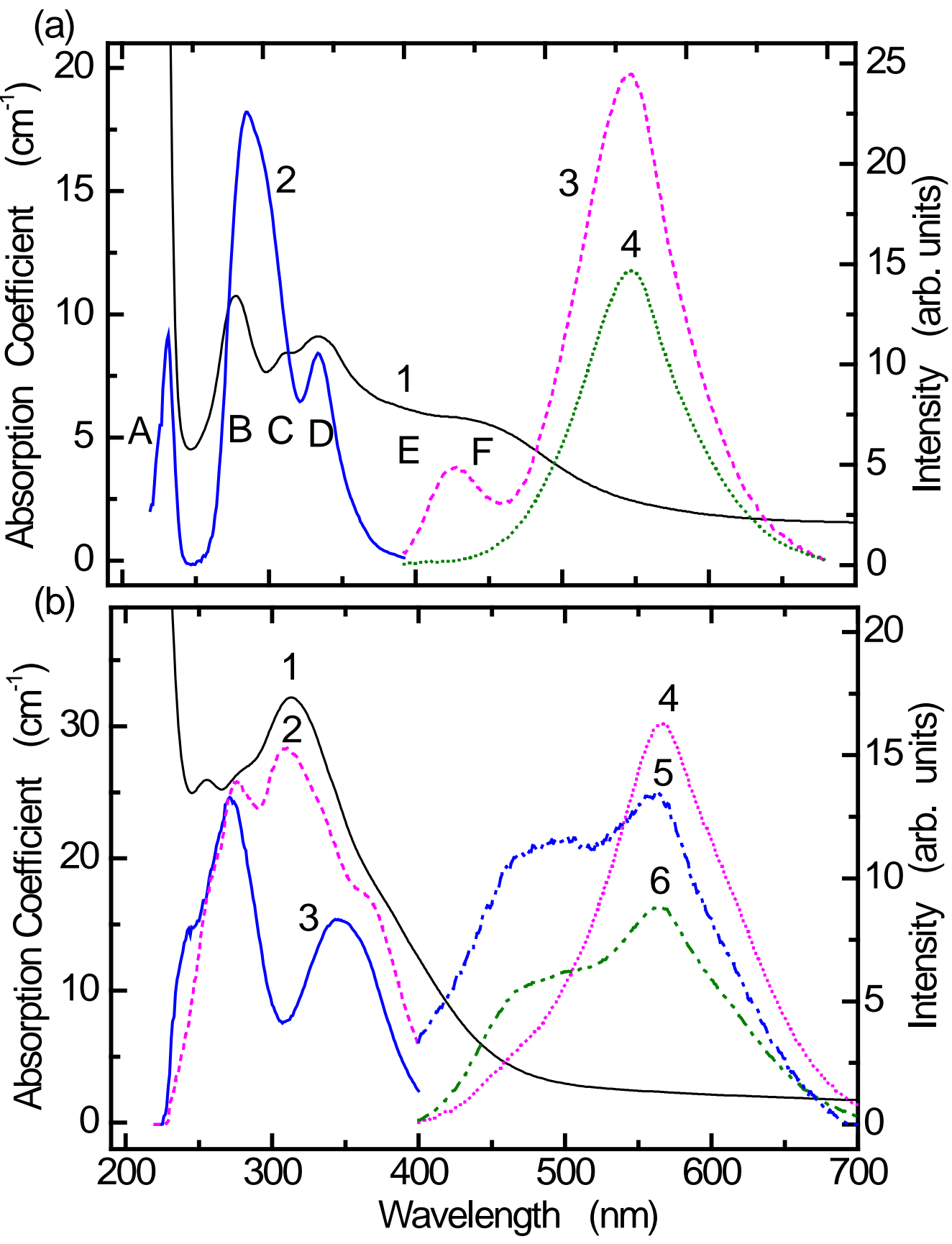

Fig. 4 (a), (b)

T. Kurobori 


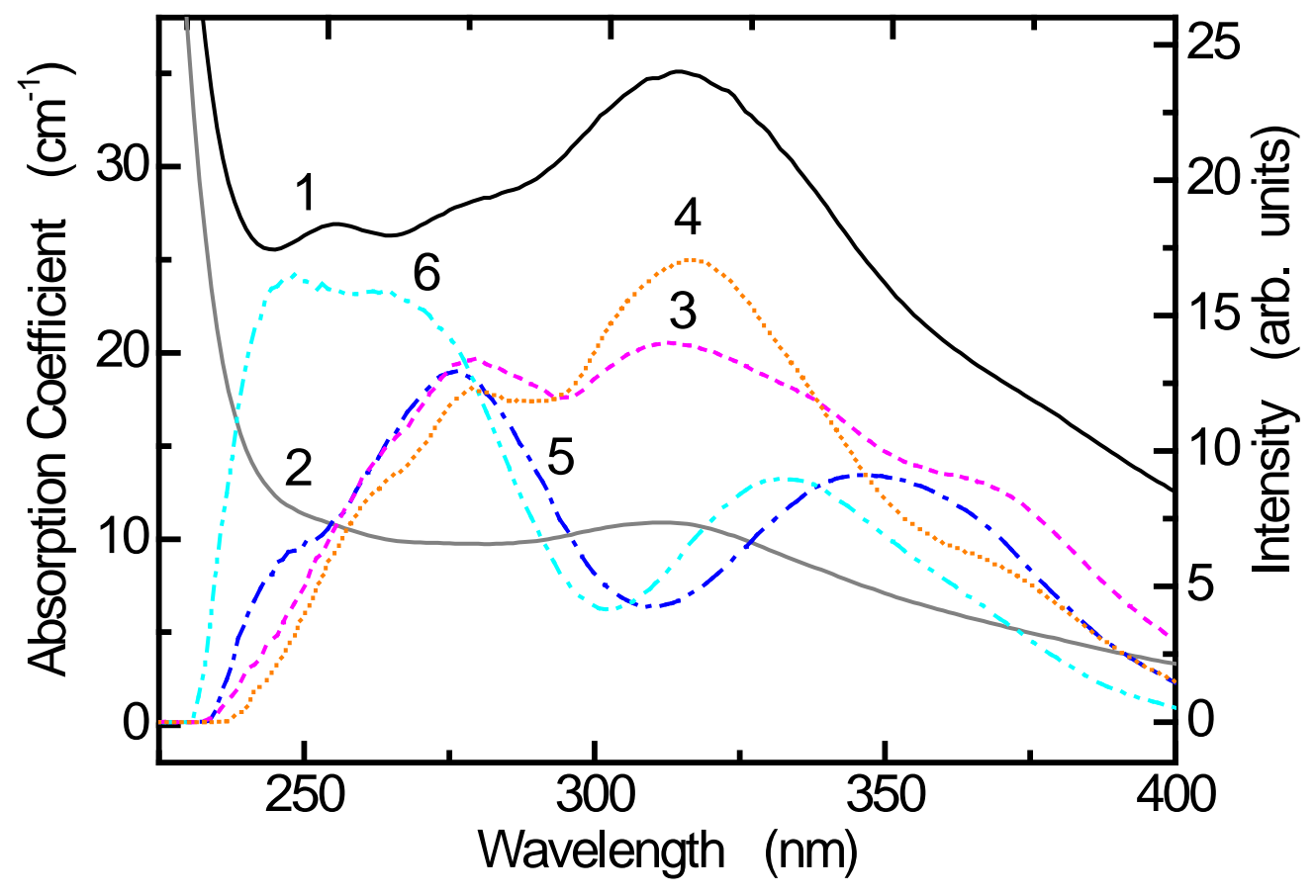

Fig. 5

T. Kurobori 


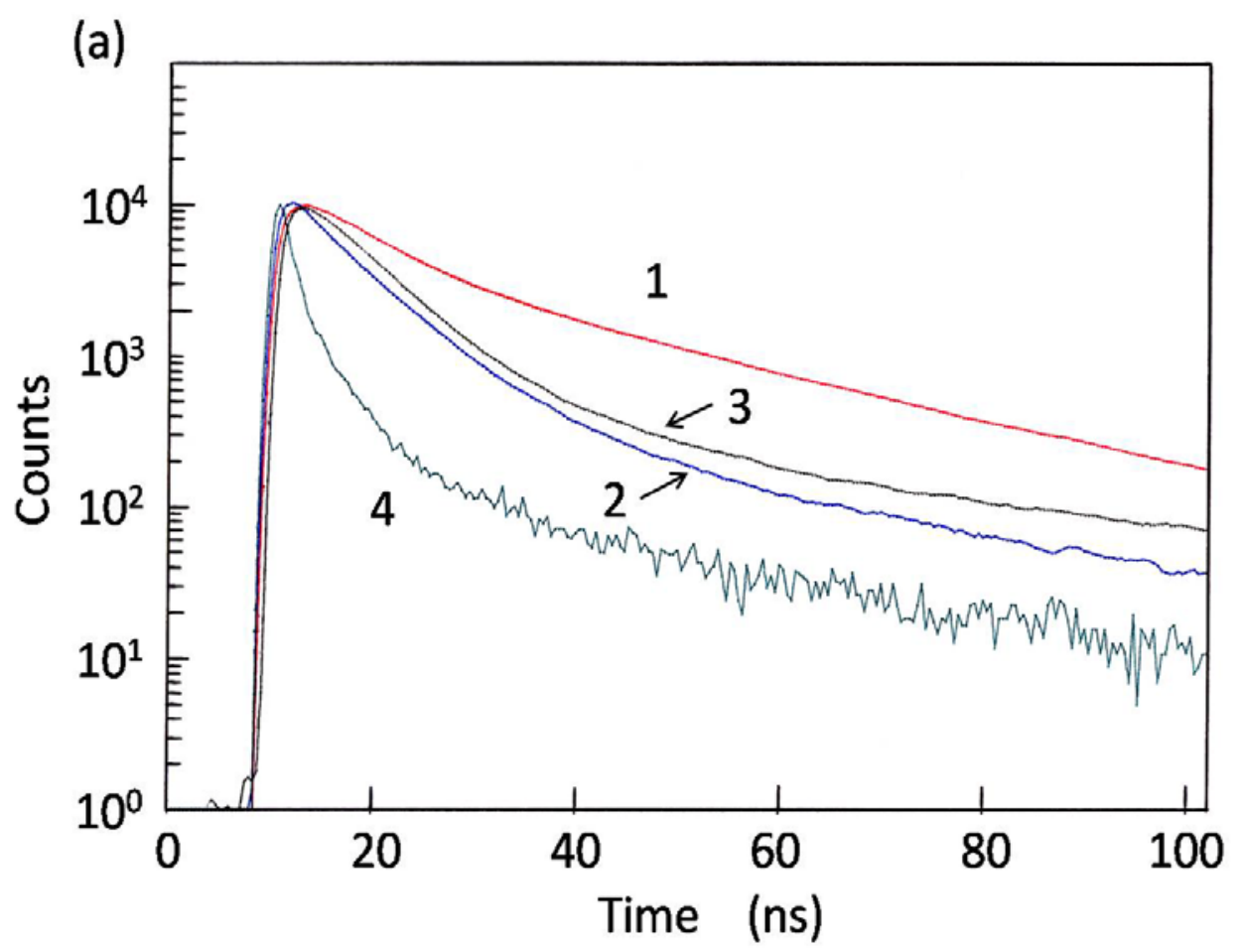

(b)

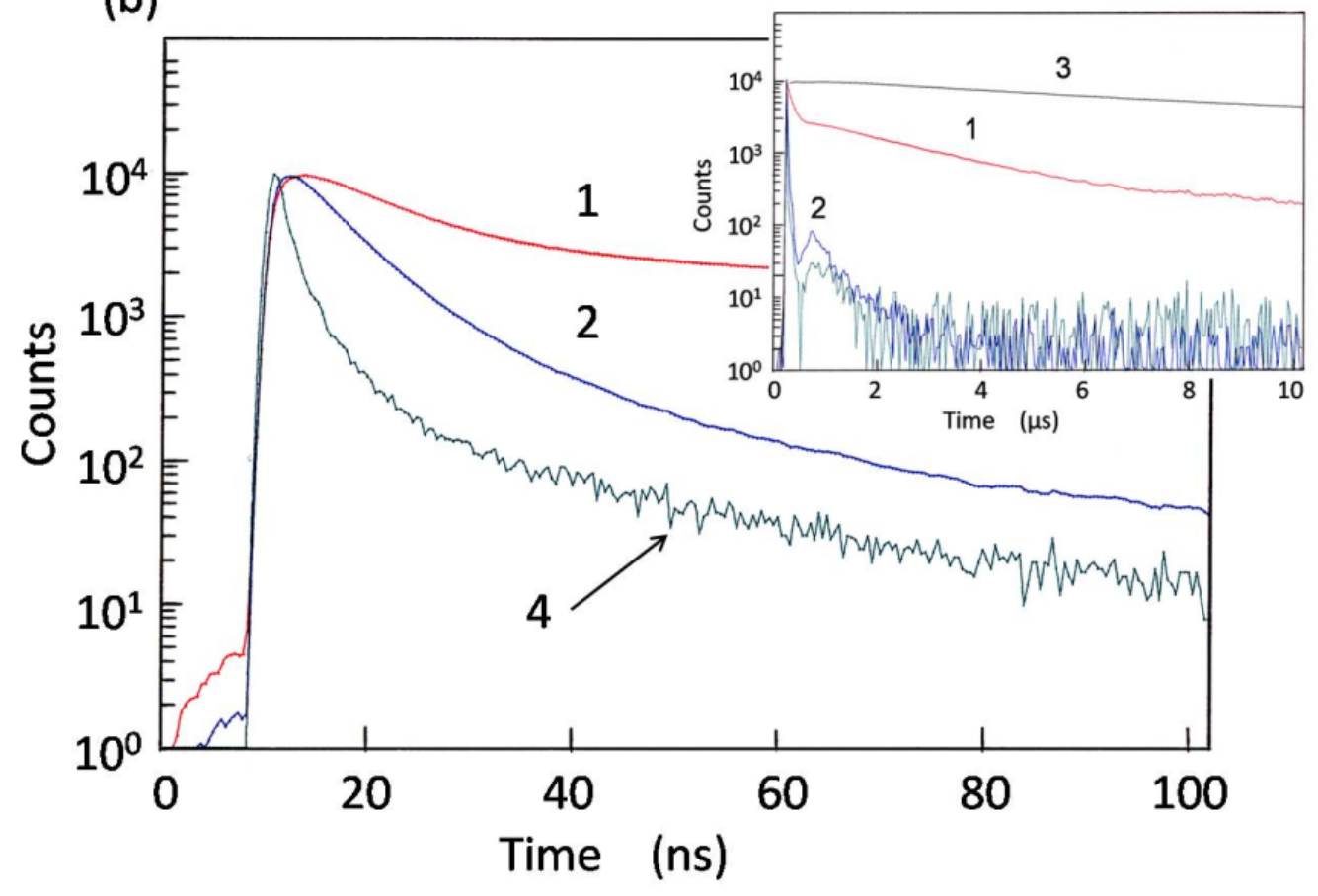

Fig. 6

(a), (b)

T. Kurobori 


\begin{tabular}{|c|c|c|c|c|c|}
\hline Materials & $\begin{array}{l}\text { Emission- } \\
\text { type }\end{array}$ & $\begin{array}{l}\text { Excitation } \\
(\mathrm{nm})\end{array}$ & $\begin{array}{l}\text { Emission } \\
(\mathrm{nm})\end{array}$ & $\begin{array}{l}\text { Lifetime } \\
\text { (ns) }\end{array}$ & $\begin{array}{l}\text { Quantum } \\
\text { efficiency } \\
(\%)\end{array}$ \\
\hline \multirow{5}{*}{$\begin{array}{l}\text { Irradiated \& unirradiated } \\
\mathrm{NaCl}: \mathrm{Ag}\end{array}$} & $\underline{P L}$ & 230 & 390 & 5.21 & 100 \\
\hline & \multirow{2}{*}{ RPL } & \multirow{2}{*}{340} & \multirow{2}{*}{450} & 1.68 & 29.6 \\
\hline & & & & 6.01 & 70.4 \\
\hline & \multirow{2}{*}{ RPL } & \multirow{2}{*}{340} & \multirow{2}{*}{560} & 5.17 & 40.7 \\
\hline & & & & 21.8 & 59.3 \\
\hline \multirow{5}{*}{$\begin{array}{l}\text { Irradiated \& unirradiated } \\
\text { PG:Ag }\end{array}$} & $\underline{P L}$ & 230 & 300 & 8600 & 100 \\
\hline & \multirow{2}{*}{ RPL } & \multirow{2}{*}{340} & \multirow{2}{*}{450} & 2.08 & 43.0 \\
\hline & & & & 6.57 & 57.0 \\
\hline & \multirow{2}{*}{ RPL } & \multirow{2}{*}{340} & \multirow{2}{*}{560} & 7.28 & 22.2 \\
\hline & & & & 2180 & 77.8 \\
\hline
\end{tabular}




\begin{tabular}{lllll}
\hline $\begin{array}{l}\text { Dose } \\
\text { (Gy) }\end{array}$ & $\begin{array}{l}\text { Lifetime (ns) } \\
\text { at 450 nm }\end{array}$ & $\begin{array}{l}\text { Quantum } \\
\text { efficiency (\%) }\end{array}$ & $\begin{array}{l}\text { Lifetime (ns) } \\
\text { at } 560 \mathrm{~nm}\end{array}$ & $\begin{array}{l}\text { Quantum } \\
\text { efficiency (\%) }\end{array}$ \\
\hline \multirow{2}{*}{24.5} & 2.08 & 43.0 & 7.28 & 15.4 \\
& 6.57 & 57.0 & 2180 & 84.6 \\
\hline \multirow{2}{*}{12.2} & 2.90 & 59.0 & 7.50 & 9.7 \\
& 7.80 & 41.0 & 1780 & 90.3 \\
\hline \multirow{2}{*}{2.45} & 3.07 & 68.3 & 8.05 & 7.9 \\
& 9.14 & 31.7 & 1840 & 92.1 \\
\hline \multirow{2}{*}{1.22} & 3.35 & 79.9 & 7.41 & 7.6 \\
& 11.4 & 20.1 & 3650 & 92.4 \\
\hline
\end{tabular}

